http://revped.ise.ro

Print ISSN 0034-8678; Online ISSN: 2559 - 639X

\title{
ATTITUDE OF HIGH SCHOOL STUDENTS TOWARDS THE USE OF TECHNOLOGY IN THE EDUCATIONAL PROCESS
}

\author{
ATITUDINEA ELEVILOR DE LICEU FAŢĂ DE UTILIZAREA TEHNOLOGIEI ÎN \\ PROCESUL EDUCATIONAL
}

\section{Lavinia DRĂGAN}

\author{
Journal of Pedagogy, 2019 (1), 161 - 174 \\ https://doi.org/10.26755/RevPed/2019.1/161
}

The online version of this article can be found at: http://revped.ise.ro/category/2019-en/

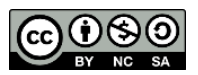

This work is licensed under the Creative Commons Attribution-NonCommercial-ShareAlike 4.0 International License. To view a copy of this license, visit http://creativecommons.org/licenses/by-nc-sa/4.0/ or send a letter to Creative Commons, PO Box 1866, Mountain View, CA 94042, USA.

Published by:

\section{INSTITUTUL DE ȘTIINTTE ALE EDUCAȚIEI}

http://www.ise.ro/

Further information about Revista de Pedagogie - Journal of Pedagogy can be found at:

Editorial Policy: http://revped.ise.ro/editorial-policy/

Author Guidelines: http://revped.ise.ro/the-writer-guide-2/ 


\title{
ATITUDINEA ELEVILOR DE LICEU FA Ă DE UTILIZAREA TEHNOLOGIEI ÎN PROCESUL EDUCA IONAL
}

\author{
Universitatea din Bucureşti, \\ Facultatea de Sociologie şi Asisten ă Socială, \\ Bucureşti, România \\ laviniadragan@gmail.com
}

\section{Lavinia Drăgan*}

\section{Rezumat}

Această lucrare prezintă rezultatele unei anchete sociologice bazate pe tehnica sondajului de opinie, utilizând ca instrument chestionarul tematic. Atât prin modul de construire a eşantionului (eşantion de disponibilitate alcătuit dintr-un număr relativ mic de subiec i), cât şi prin analiza şi interpretarea datelor, prezenta cercetare este relativ asemănătoare studiilor calitative. Chestionarul se adresează elevilor de liceu şi este elaborat cu scopul de a analiza percep iile şi atitudinile acestora cu privire la utilizarea tehnologiei în procesul de învă are şi evaluare. Am avut în vedere atât gradul de utilizare a tehnologiei pentru studiul individual şi documentare, cât şi nivelul de valorificare de către profesori şi elevi a acesteia în cadrul lec iilor. Ancheta sociologică pe bază de chestionar surprinde şi modul în care responden ii privesc felul în care tehnologia poate fi utilizată în domeniul predării ştiin elor socio-umane.

Pornind de la dezvoltarea celor opt competen e cheie stabilite în conformitate cu normele europene, am investigat modalitatea în care, pe lângă competen ele generale şi specifice prevăzute de programa de sociologie, se poate urmări şi dezvoltarea competen elor digitale.

Rezultatele cercetării indică un nivel crescut de receptivitate şi de interes din partea elevilor fa ă de integrarea tehnologiei în cadrul predării ştiin elor socio-umane, precum şi o creştere a eficien ei în raport cu obiectivele didactice propuse.

* Drd., Facultatea de Sociologie şi Asisten ă Socială, Universitatea din Bucureşti, România. 
De asemenea, se poate constata o creştere a motiva iei intrinseci pentru studiu şi asumarea unui rol activ de către elevi pe parcursul procesului educa ional.

În concluzie, integrarea tehnologiei în strategiile didactice utilizate în procesul de predare-învă are-evaluare se dovedeşte a fi benefică, venind în egală măsură în întâmpinarea nevoilor elevilor şi ale profesorilor.

Cuvinte-cheie: competen e digitale, liceu, ştiin e socio-umane, tehnologie.

\section{Abstract}

This paper takes into account the results of a sociological survey based on the opinion poll technique, using a thematic questionnaire. The sample construction (availability sample of a relatively small number of subjects) and the data analysis and interpretation make this research similar to qualitative studies. The questionnaire addresses high school students and it is designed to analyze their perceptions and attitudes about the use of technology in learning and assessment. Both the degree of technology use during individual study and research and the level of capitalization by teachers and pupils during lessons were taken into consideration.

The sociological survey also captures the respondents'opinions on how technology can be used in teaching social science.

Taking into account the development of eight key competences established in accordance with the European norms, the way in which digital competencies development can be pursued - besides the general and specific competencies provided by the sociology curriculum - has been investigated.

The research results indicate an increased level of students' receptivity and interest towards the integration of technology in teaching social science, as well as an increase in efficiency regarding teaching aims and objectives.

Also, an increase in learners' intrinsic motivation to study and their willingness to play an active role in the educational process can be observed.

In conclusion, integrating technology into the teaching-learning-evaluation process proves to be beneficial, equally meeting the needs of students and teachers.

Keywords: digital competencies, highschool, social science, technology. 
Pornind de la precizarea conform căreia „Tehnologia pedagogică reprezintă „ansamblul tehnicilor și cunoştin elor practice imaginat pentru a organiza, atesta şi a asigura func ionalitatea institu iei şcolare la nivel de sistem (De Landsheere, Gilbert, 1992, p. 294)”, pe care Sorin Cristea o prezintă în preambulul definirii acestui concept în Dic ionar de termeni pedagogici (Cristea, 1998, p. 285) am derulat o cercetare empirică. În acest demers am avut în vedere două dintre cele patru dimensiuni opera ionale ale „, conceptului de tehnologie a educa iei/instruirii”, şi anume: ,... pregătirea şi folosirea materialului pedagogic; aplicarea cunoştin elor în activitatea de învă are" (Cristea, 1998, p.285).

Este de notorietate faptul că adolescen ii manifestă un interes deosebit fa ă de tehnologia modernă, cu precădere pentru activită i care in de domeniul divertismentului, al comunicării interpersonale şi al informării curente, aspecte care in de educa ia non-formală şi de cea informală. Introducerea mijloacelor tehnologice în sistemului educa ional formal reprezintă o necesitate şi vine în întâmpinarea acestui gen de interes din partea unui segment social care se află în plin proces de formare.

Mai mult, abilitatea şi disponibilitatea tinerei genera ii - definită de Marc Prensky drept o genera ie de „nativi digitali” (Prensky, 2001) - pentru utilizarea mijloacelor tehnologice constituie o oportunitate care poate fi canalizată eficient, atât în scopul atingerii obiectivelor generale ale sistemului educa ional formal, cât şi pentru a consolida o conduită corectă de raportare la aceste modalită i de comunicare şi de exprimare socială. $\mathrm{Cu}$ alte cuvinte, folosirea noilor tehnologii ar trebui să conducă la dobândirea unui nivel de „, in elepciune digitală", concept atribuit tot de Marc Prensky persoanelor care sunt capabile să utilizeze cu discernământ tehnologia digitală (Prensky, 2009), astfel încât să poată selecta, tria şi ierarhiza în mod responsabil informa iile furnizate pe această cale.

Această problematică reprezintă un interes nu numai la nivel local, na ional sau european, ci şi la nivel mondial. Este relevant în acest context raportul final al studiului „Internetul şi mediile de socializare virtuale în via a liceenilor", realizat de Institutul de Ştiin e ale Educa iei şi publicat în 2017. În acest raport, capitolul Statistici comparative România - Uniunea Europeană (pp.8-14), elaborat de Irina Boeru, ilustrează, prin date statistice, 
situa ia existentă la nivelul ării noastre sub acest aspect, iar capitolul Politici publice în domeniul formării competen elor digitale (pp.15-25), elaborat de Sorin Mitulescu şi Ioana Ştefănescu, prezintă cadrul general al preocupărilor pentru acest domeniu atât la nivel na ional, cât şi la nivel interna ional.

Este de remarcat faptul că încă din 2003, în procesul de parcurgere a etapelor de aderare la Uniunea Europeană, legisla ia românească urmăreşte integrarea politicilor manifestate la nivel interna ional. Desigur, to i aceşti paşi făcu i de România sunt foarte importan i, însă procesul de dezvoltare şi schimbările de natură tehnologică sunt deosebit de dinamice şi au un impact din ce în ce mai amplu asupra vie ii de zi cu zi, inclusiv în ceea ce priveşte sistemul de învă ământ.

În acest sens, în cadrul prezentei cercetări am avut în vedere faptul că mijloacele tehnologice reprezintă instrumente care pot sus ine diferitele tipuri de activită i şi în nici un caz nu le pot înlocui. Acestea, ca orice alte instrumente, pot fi utilizate atât în scopuri benefice, cât şi reprobabile, însă, în orice caz fetişizarea sau blamarea lor constituie pozi ii extreme care trebuie evitate.

Obiectivul acestei cercetări empirice este identificarea atitudinilor, percep iilor şi a gradului de mul umire a elevilor din ciclul superior al învă ământului liceal cu privire la utilizarea mijloacelor tehnologice în procesul educa ional formal.

Astfel, am optat pentru analiza preponderent calitativă a informa iilor ob inute, folosind ca metodă de cercetare ancheta sociologică bazată pe tehnica sondajului de opinie, care a utilizat ca instrument un chestionar alcătuit din 10 întrebări, dintre care 9 închise şi o întrebare mixtă.

Chestionarul propus este structurat inând cont de patru dimensiuni opera ionale relevante în procesul de predare-învă are-evaluare, iar rolul fiecăreia dintre ele este explicitat în cele ce urmează.

Prima dimensiune se referă la percep iile şi atitudinile cu privire la utilizarea tehnologiei în procesul educa ional şi vizează identificarea 
gradului de disponibilitate a elevilor în raport cu introducerea noilor tehnologii, ceea ce ar putea conduce la o implicare mai mare a acestora în activitatea şcolară.

A doua dimensiune avută în vedere urmăreşte să surprindă gradul de utilizare a tehnologiei pentru studiul individual, documentare şi evaluare, astfel încât metodele de predare să se armonizeze cu metodele de studiu utilizate frecvent de elevi.

Cea de-a treia dimensiune se axează pe elemente specifice cu privire la percep iile asupra nivelului de valorificare de către profesori şi elevi a tehnologiei în cadrul lec iilor, pentru a releva măsura în care aceasta vine în sprijinul procesului de predare-învă are-evaluare.

A patra dimensiune se referă la percep iile elevilor asupra dezvoltării celor opt competen e cheie stabilite în conformitate cu normele europene, prin utilizarea mijloacelor tehnologice în procesul educa ional, ceea ce urmăreşte eviden ierea rolului propriu-zis pe care îl pot de ine noile tehnologii în procesul educa ional în ansamblul său.

Această anchetă sociologică pe bază de chestionar vizează un eşantion de disponibilitate, prin care se urmăreşte surprinderea aspectelor mai sus enun ate, precum şi deschiderea unor noi direc ii de cercetare.

O limită a prezentei cercetări decurge din faptul că rezultatele anchetei nu pot fi generalizate la întreaga popula ie pe care o reprezintă elevii de liceu, atât ca urmare a tipului de eşantion utilizat, cât şi a faptului că grupul investigat este alcătuit din doar 100 de elevi din ciclul liceal superior, reziden i în Bucureşti, cu vârste cuprinse între 16 şi 19 ani la data aplicării chestionarului. De asemenea, o altă limită derivă din faptul că ancheta surprinde exclusiv opiniile elevilor, fără a investiga şi pozi ia cadrelor didactice cu privire la tema cercetării.

Trebuie precizat faptul că datele înregistrate sunt raportate la numărul de răspunsuri acordate, acesta fiind variabil, deoarece la unele întrebări responden ii au putut opta pentru una sau mai multe variante de răspuns. 
În cele ce urmează voi prezenta analiza răspunsurilor şi interpretarea datelor ob inute pentru fiecare dintre întrebările chestionarului pe tema percep iei elevilor de liceu asupra utilizării mijloacelor tehnologice în procesul educa ional.

Întrebarea nr. 1. Marca i cât de frecvent sunt utilizate în timpul orelor de curs mijloacele tehnologice de uz comun (de exemplu: proiector, tablă interactivă, monitor PC etc.).

Această întrebare vizează două dintre cele patru dimensiuni opera ionale enun ate anterior şi anume: cea care are în vedere surprinderea percep iilor şi atitudinilor elevilor cu privire la măsura utilizării tehnologiei în procesul educa ional, precum şi cea referitoare la nivelul de valorificare de către profesori şi elevi a tehnologiei în cadrul lec iilor.

Astfel, în urma prelucrării datelor pentru această întrebare s-au ob inut următoarele rezultate, care reprezintă percep ia responden ilor cu privire la frecven a utilizării mijloacelor tehnologice de uz comun în timpul orelor de curs: $8 \%$ frecvent, $47 \%$ uneori, $43 \%$ rareori, $1 \%$ niciodată, $1 \%$ N.Ş./ N.R.

Se poate observa faptul că variantele de răspuns alese preponderent au valori foarte apropiate, respectiv: $47 \%$ (uneori) şi $43 \%$ (rareori), situate la mare distan ă de celelalte variante, care înregistrează procente foarte scăzute, adică $8 \%$ (frecvent), $1 \%$ (niciodată) şi $1 \%$ (N.Ş./N.R.).

Rezultatele indică faptul că responden ii percep utilizarea mijloacelor tehnologice de uz comun într-o măsură moderată, acestea nefiind principalele modalită i de prezentare a informa iilor în timpul orelor de curs.

Întrebarea nr. 2. Marca i cât de frecvent sunt utilizate $\hat{\imath}$ t timpul orelor de curs mijloacele tehnologice de uz individual (de exemplu: mobil, tabletă, laptop etc.).

Întrebarea urmăreşte să surprindă dimensiunea opera ională referitoare la gradul de utilizare a tehnologiei pentru studiul individual, documentare şi evaluare, iar analiza răspunsurilor de la această întrebare pune în eviden ă 
următoarele rezultate: $37 \%$ frecvent, $38 \%$ uneori, $25 \%$ rareori, $0 \%$ niciodată, $0 \%$ N.S.S.N.R.

Procentul cel mai ridicat îl de ine tot varianta uneori (38\%), urmată îndeaproape de această dată de varianta frecvent (37\%), în timp ce varianta rareori are, de asemenea, un scor ridicat $(25 \%)$. Acest aspect relevă că mijloacele tehnologice de uz individual sunt folosite într-o mai mare măsură decât cele de uz comun. De remarcat este că to i responden ii declară că folosesc mai mult sau mai pu in mijloacele tehnologice în timpul orelor de curs, întrucât variantele niciodată şi N.Ş./N.R. întrunesc $0 \%$.

Următoarele două întrebări pun în eviden ă aceleaşi două dimensiuni opera ionale, care au în vedere percep ia responden ilor asupra importan ei utilizării noilor tehnologii, atât în diferite etape ale studiului individual, cât şi în cadrul procesului de predare-învă are-evaluare de la clasă.

\section{Întrebarea nr. 3. Marca $i$ scopurile pentru care utiliza $i$ mijloacele tehnologice în procesul de învă are.}

În ceea ce priveşte scopurile pentru care elevii utilizează mijloacele tehnologice în procesul de învă are, din totalul celor 169 de răspunsuri a rezultat următoarea distribu ie de procente: 48,5\% documentare, 17,2\% redactare, 28,4\% prezentare/expunere, 5,3\% altele si anume care? ......, $0,6 \%$ N.S./N.R.

Dintre variantele de răspuns, ponderea cea mai ridicată o de ine op iunea documentare $(48,5 \%)$, urmată de prezentare/expunere $(28,4 \%)$ şi de redactare $(17,2 \%)$. Trebuie subliniat faptul că elevii declară că folosesc mijloacele tehnologice preponderent în scopul documentării şi mult mai pu in pentru celelalte două.

Referitor la varianta altele şi anume care? (5,3\%), răspunsurile se grupează în două mari categorii: una care vizează tot documentarea (de exemplu: „,timp rapid de aflarea informa iilor”/,pentru orice, chiar şi pentru teme”), iar cealaltă care indică o neîn elegere a sensului întrebării (de exemplu: „, interes personal”/,distrac ie”/,,muzică”). 
Varianta de răspuns N.Ş./N.R. înregistrează un scor nesemnificativ de $0,6 \%$.

Întrebarea nr. 4. Ordona i în func ie de importan ă scopurile pentru care utiliza i mijloacele tehnologice ( 1 = cel mai important, $3=$ cel mai pu in important).

În mod similar, la această întrebare observăm că se men ine aceeaşi ierarhie a scopurilor principale pentru care responden ii utilizează mijloacele tehnologice în procesul educa ional (documentare, prezentare/expunere, redactare), precum şi aceeaşi pondere a rezultatelor.

Astfel, responden ii acordă în propor ie de $72 \%$ locul întâi (cel mai important) pentru documentare, în timp ce $17 \%$ dintre responden i plasează această variantă pe locul al doilea şi doar 6\% pe locul al treilea (cel mai pu in important).

Varianta de răspuns prezentare/expunere este aleasă pentru a doua pozi ie de $42 \%$ dintre responden i, iar 35\% îi acordă locul al treilea şi doar $18 \%$ locul întâi.

Pentru redactare, 55\% acordă locul trei, considerând că acest scop este cel mai pu in important, în condi iile în care $36 \%$ îl plasează pe locul al doilea şi numai $4 \%$ îl percep ca fiind cel mai important.

Trebuie men ionat că $3 \%$ dintre responden i au dat răspunsuri nevalide şi $2 \%$ au optat pentru varianta N.Ş./N.R.

Întrebarea nr. 5. Cât considera $i$ că vă motivează utilizarea mijloacelor tehnologice în timpul orelor de curs?

Dimensiunea opera ională referitoare la percep iile şi atitudinile cu privire la utilizarea tehnologiei în procesul educa ional este relevată şi de această întrebare, care în acest caz sondează punctual motiva ia elevilor în legătură cu acest aspect. Astfel, în urma prelucrării datelor s-au ob inut următoarele rezultate: $38 \%$ mult, $45 \%$ moderat, $10 \%$ pu in, $5 \%$ deloc, $2 \%$ N.S../N.R. 
Se observă că cei mai mul i dintre responden i consideră că utilizarea mijloacelor tehnologice în timpul orelor de curs îi motivează moderat (45\%) şi mult (38\%), în timp ce la o distan ă semnificativă îi întâlnim pe cei care se declară pu in (10\%) şi deloc (5\%) motiva i. Doar $2 \%$ dintre responden i au optat pentru varianta N.Ş./N.R..

Numărul celor care se declară $p u$ in şi deloc motiva i poate indica faptul că mijloacele tehnologice în sine nu sunt suficiente pentru a stimula activitatea elevilor în timpul orelor de curs.

Trebuie precizat faptul că în elaborarea chestionarului s-au avut în vedere atât complexitatea procesului de învă are, cât şi diferitele aspecte ale implementării şi utilizării tehnologiei moderne în actul educa ional. Acest aspect a determinat ca formularea primelor cinci întrebări să eviden ieze numai una sau două dintre dimensiunile opera ionale amintite, în timp ce fiecare dintre următoarele cinci întrebări, ale căror rezultate vor fi prezentate în continuare, conduc la concluzii relevante pentru toate cele patru dimensiuni semnificative în procesul de predare-învă are-evaluare.

Întrebarea nr. 6. Cât considera $i$ că vă ajută utilizarea mijloacelor tehnologice în procesul de învă are?

Percep ia responden ilor cu privire la ajutorul oferit de utilizarea mijloacelor tehnologice în procesul de învă are înregistrează următoarele rezultate: $61 \%$ mult, 33\% moderat, $3 \%$ pu in, $2 \%$ deloc, $1 \%$ N.Ş./N.R.

Majoritatea elevilor sus in că mijloacele tehnologice îi ajută mult (61\%), în timp ce $33 \%$ declară că acestea îi ajută moderat. La distan ă considerabilă se situează scorurile ob inute pentru variantele de răspuns pu in (3\%) şi deloc (2\%). Varianta N.S../N.R. a înregistrat $1 \%$.

\section{Întrebarea nr. 7. Marca i gradul de mul umire fa ă de orele de curs în care sunt utilizate mijloacele tehnologice.}

Prelucrarea datelor referitoare la gradul de mul umire a elevilor fa ă de orele de curs în care sunt utilizate mijloacele tehnologice eviden iază 
următoarele rezultate: $43 \%$ ridicat, $50 \%$ mediu, $5 \%$ scăzut, $2 \%$ N.Ş./ N.R.

Jumătate dintre responden i manifestă un grad mediu de mul umire (50\%), fiind urma i îndeaproape de cei care exprimă un grad ridicat de mul umire (43\%) în ceea ce priveşte utilizarea mijloacelor tehnologice în orele de curs. Se observă şi faptul că cele două variante de răspuns care însumează o pondere considerabilă indică o deschidere a elevilor pentru utilizarea mijloacelor tehnologice în procesul educa ional şi doar 5\% dintre responden i manifestă un grad scăzut de mul umire. Varianta de răspuns N.Ş./N.R. are un procent de $2 \%$.

\section{Întrebarea nr. 8. Pentru care dintre următoarele tipuri de activită $i$ şcolare utiliza i mijloacele tehnologice?}

La această întrebare responden ii au putut opta pentru una sau mai multe variante de răspuns, ceea ce a generat următoarea frecven ă a celor 116 răspunsuri consemnate: $60,3 \%$ predominant teoretice, $14,7 \%$ predominant practice, 19,8\% predominant creative, 5,2\% N.Ş./N.R.

Se poate remarca ponderea detaşată a op iunilor pentru utilizarea mijloacelor tehnologice în cazul activită ilor şcolare predominant teoretice $(60,3 \%)$, pe locul al doilea situându-se activită ile predominant creative $(19,8 \%)$, urmate de cele predominant practice $(14,7 \%)$. În acest caz se înregistrează un procent relativ ridicat de non-răspunsuri $(5,2 \%)$.

\section{Întrebarea nr. 9. Cum aprecia $i$ folosirea mijloacelor tehnologice în predarea ştiin elor socio-umane?}

Percep ia elevilor fa ă de folosirea mijloacelor tehnologice în predarea ştiin elor socio-umane este relevată de următoarele procente: $85 \%$ utilă, $3 \%$ inutilă, $11 \%$ N.S../N.R., $1 \%$ răspunsuri nevalide.

Un procent foarte ridicat de responden i (85\%) apreciază că folosirea acestor mijloace este utilă în predarea ştiin elor socio-umane, în contrast cu 3\%, care o percep ca inutilă . Un aspect surprinzător îl constituie nivelul mare de non-răspunsuri (11\%) la care se adaugă şi 1\% răspunsuri nevalide. 
Întrebarea nr. 10.Pe lângă competen ele digitale, care dintre competen ele stabilite în conformitate cu normele europene pentru educa ia şi formarea pe tot parcursul vie ii, considera $i$ că vă sunt dezvoltate prin utilizarea mijloacelor tehnologice în cadrul orelor de curs?

În urma prelucrării datelor care reprezintă percep iile elevilor cu privire la rolul mijloacelor tehnologice în dezvoltarea altor competen e, pe lângă cele digitale, au rezultat 290 de răspunsuri, deoarece întrebarea permitea op iuni multiple. Astfel, s-au ob inut următoarele rezultate: $8,3 \%$ comunicarea in limba maternă, 30,7\% comunicarea în limbi străine, 5,9\% competen e matematice şi competen e de bază în ştiin ă şi tehnologie, $11,7 \%$ a învă a să înve $i, 15,9 \%$ competen e sociale şi civice, $14,1 \%$ spirit de ini iativă şi antreprenoriat, 13,1\% sensibilitate şi exprimare culturală, $0,3 \%$ N.Ş./ N.R.

Cel mai ridicat procent se observă la comunicarea în limbi străine (30,7\%), în timp ce valorile cele mai scăzute sunt înregistrate pentru competen e matematice şi competen e de bază în ştiin ă şi tehnologie (5,9\%) şi comunicarea în limba maternă $(8,3 \%)$. Pentru celelalte patru competen e s-au ob inut rezultate relativ apropiate. Astfel, pentru a învă a să înve $i-$ $11,7 \%$, pentru competen e sociale şi civice - $15,9 \%$, pentru spirit de ini iativă şi antreprenoriat - $14,1 \%$ şi pentru sensibilitate şi exprimare culturală $13,1 \%$. Un procent nesemnificativ îl reprezintă varianta N.Ş./N.R., pentru care s-a optat în propor ie de $0,3 \%$.

Concluziile cercetării empirice care se desprind din prelucrarea datelor ob inute în urma aplicării acestui chestionar sunt prezentate în cele ce urmează.

Măsura în care sunt folosite mijloacele tehnologice în procesul educa ional formal le permite elevilor de liceu din eşantionul investigat să formuleze aprecieri referitoare la acest aspect. Astfel, în raport cu situa iile în care acestea sunt utilizate, rezultă că cele de uz comun sunt folosite într-o mai mică măsură în timpul orelor de curs (vezi frecven ele pentru întrebarea 1: $47 \%$ uneori şi $43 \%$ rareori), spre deosebire de cele de uz individual (vezi frecven ele de la întrebarea 2: $38 \%$ uneori şi $37 \%$ frecvent). 
Pe de o parte, atitudinea deschisă şi dorin a clar exprimată de elevi pentru utilizarea mijloacelor tehnologice nu numai pentru divertisment, relaxare sau ca mediu de socializare, ci şi în procesul educa ional formal, reiese din valorile ridicate $(45 \%$ moderat şi $38 \%$ mult) ob inute la întrebarea 5 referitoare la gradul de motivare pentru utilizarea mijloacelor tehnologice în timpul orelor de curs. Pe de altă parte, la aceeaşi întrebare, procentul responden ilor care se declară pu in (10\%) şi deloc (5\%) motiva i se poate explica prin faptul că simpla utilizare a mijloacelor tehnologice nu este suficientă pentru a asigura implicarea mai activă a elevilor la orele de curs.

O altă idee care rezultă din răspunsurile elevilor (vezi răspunsurile de la întrebarea 8) este aceea că mijloacele tehnologice sunt insuficient folosite în cadrul activită ilor predominant practice $(14,7 \%)$ şi predominant creative $(19,8 \%)$, spre deosebire de cele predominant teoretice $(60,3 \%)$, care se situează pe primul loc la distan ă mare. De asemenea, se poate observa că aceste valori corelează cu cele ob inute la întrebările 3 şi 4, referitoare la scopurile utilizării mijloacelor tehnologice, la care responden ii consideră activitatea de documentare ca fiind cea mai importantă (48,5\% la întrebarea 3), plasând-o pe prima pozi ie în op iunile lor la întrebarea 4.

Un aspect îmbucurător este cel relevat de răspunsurile la întrebarea 10, care dovedesc că responden ii conştientizează faptul că utilizarea mijloacelor tehnologice contribuie la consolidarea generală a competen elor stabilite în conformitate cu normele europene pentru educa ia şi formarea pe tot parcursul vie ii, ceea ce ar trebui să constituie o încurajare pentru dotarea unită ilor de învă ământ în vederea asigurării unui cadru atractiv pentru elevi şi din acest punct de vedere.

În acelaşi context se poate plasa şi interpretarea răspunsurilor de la întrebarea 9, la care majoritatea elevilor (85\%) sunt de părere că utilizarea mijloacelor tehnologice în cadrul orelor de ştiin e socio-umane este utilă , ceea ce poate conduce la oportunitatea înfiin ării în viitor a unor laboratoare/cabinete destinate disciplinelor din această arie curriculară. Dotarea acestora cu sisteme audio-video care să faciliteze experimentarea unor proceduri specifice (anchete sociologice, interpretări ale datelor ob inute din chestionare, prezentări video ale unor cazuistici sociale), ar putea permite 
ca activitatea teoretică să-şi găsească o prelungire cu caracter aplicativ, specifică vie ii curente.

O concluzie cu caracter general şi în egală măsură o aten ionare pentru sistemul educa ional formal o reprezintă prioritatea op iunii elevilor în utilizarea mijloacelor tehnologice cu scopul principal de documentare. Această situa ie poate conduce la ideea falsă că ar exista o echivalen ă între expunerea con inuturilor aferente disciplinelor şcolare şi informa iile, nu întotdeauna corecte, ob inute prin intermediul mijloacelor tehnologice. În fapt, cele două modalită i de informare nu se exclud, ci dimpotrivă, se poten ează reciproc.

Deoarece în prezent sistemul educa ional formal nu mai de ine monopolul asupra furnizării informa iilor, acestuia îi revine rolul de a îi învă a pe elevi cum să gestioneze procesul de documentare, diminuând astfel riscul de utilizare a unor informa ii viciate furnizate din varii surse, inclusiv din zona internetului.

\section{Mul umiri:}

Mul umesc tuturor elevilor care au acceptat să participe la această cercetare, prin răspunsurile acordate la chestionar.

\section{Referin e}

- Boeru, I., Dalu, A.M., Iftode, O., Manu, M., Mitulescu, S., Neacşu-Dalu, C.C., Plăeşu, A., \& Ştefănescu, I. (2017). Internetul şi mediile de socializare virtuale in via a liceenilor. Bucureşti. Disponibil la https://www.ise.ro/internetul-simediile-de-socializare-virtuale-in-viata-liceenilor (accesat la 31.05.2019).

- Cristea, S. (1998). Dic ionar de termeni pedagogici. Bucureşti: Editura Didactică şi Pedagogică.

- Prensky, M. (2001). Digital Natives, Digital Immigrants. In: On the Horizon, MCB University Press (Vol.9, No.5). MCB University Press. https://doi.org/10.1108/10748120110424816.

- Prensky, M. (2009). H. Sapiens Digital: From Digital Immigrants and Digital Natives to Digital Wisdom. 
The online version of this article can be found at: http://revped.ise.ro/category/2019-en/

\section{(cc) $B Y-N C-S A$}

This work is licensed under the Creative Commons Attribution-NonCommercial-ShareAlike 4.0 International License.

To view a copy of this license, visit http://creativecommons.org/licenses/by-nc-sa/4.0/ or send a letter to Creative Commons, PO Box 1866, Mountain View, CA 94042, USA.
Versiunea online a acestui articol poate fi găsită la: http://revped.ise.ro/category/2019-ro/

\section{(cc) B B-NC-sA}

Această lucrare este licen iată sub Creative Commons Attribution-NonCommercial-ShareAlike 4.0 International License.

Pentru a vedea o copie a acestei licen e, vizita $i$ http://creativecommons.org/licenses/by-nc-sa/4.0/ sau trimite i o scrisoare către Creative Commons, PO Box 1866, Mountain View, CA 94042, SUA. 